\title{
Speaking of language and culture: A report on the conference "Approaches to Migration, Language, and Identity"
}

Gian Hernandez, USI - Università della Svizzera italiana, Faculty of Communication Sciences gian.louis.hernandez@usi.ch

The entwined phenomena of migration, language and identity occupy a unique global position. Global mobility influences how human beings relate to one another on geographic, political, and social scales, and these connections and their individual parts stand in a mutually constitutive relationship. It is of utmost importance that academic discourses on these topics are addressed in ways that help positively shape the effects of global flows. Therefore, Anita Auer and Jennifer Thorburn from the University of Lausanne held a three-day conference from the $4^{\text {th }}$ to the $6^{\text {th }}$ of May 2017 at their university, which provided an interdisciplinary forum for discussion of concepts, ideas, and methods for researching migration, language, and identity. Scholars from around the world and across disciplines arrived to discuss the interrelated nature of these concepts. The participants also discussed the implications of theory and research for practitioners working with migrants as well as for teachers and professionals from various disciplines.

The focus of the conference's first day was on how to contextualize the formation of identities. In an increasingly globalized public media sphere, the importance of media studies on this topic should not be understated. As Fairclough (1995) has noted, any part of a (media) text is responsible for representation, establishment, and relation of identities. This tells us that media provide insight into the ways in which identities are formed relationally, a key aspect of the conference. It is important to contextualize how and why these representations and relations are established, particularly in Switzerland, whose public media sphere is both linguistically and ideologically diverse. In an incisive article on the Swiss context, Wessendorf (2008) highlighted the underlying motivations for discourses surrounding citizenship debates. By revealing the culturalist discourse of various media texts on these debates, the article demonstrated the discursive power of the media as well as fundamental conceptualizations of how Swiss identity is discursively constructed. This is just one example of the many ways in which media analyses expose modes of communication that are often taken for granted. The textual focus of the first day of the conference signified a deeper interest in (con)textualizing how representations of identities function.

One of the plenary speakers for this occasion, Naomi Tadmor, illustrated the historical development of the social welfare system in seventeenth- and eighteenthcentury England. An analysis of this "poor relief system," directly concerned with migration, serves to illuminate current debates surrounding the concept of deservingness in regards to social benefits. Her enlightening presentation gave insight into the polemical question, "who was entitled to relief?" (Tadmor, 2017). She highlighted parallels between the bureaucratization of the relatively new technologies of seventeenth- and eighteenth-century England and the current developments in processing migrant claims for livelihood. She spoke to a growing concern within migration studies: the central position of migrant documentation. Throughout the presentation, the echoes of historical administrative paper-rustling resonated with the endless paper trail along which today's migrants must travel. As textual analysis, Professor Tadmor's contribution set the 
stage for deeper engagement with the various themes of the conference.

Many of the presentations examined how texts, specifically literary texts, explicate social phenomena in the context of migration. As a genre, literary studies offers insight into the broader contexts of human interaction. Migrant literature in particular reflects the ever-changing dynamics of a society. The literature discussed throughout the conference illuminated issues relevant to the migrant experience on national and international levels. For example, an account of the Algerian poet Jean Sénac and his fight for freedom showed conference participants the emancipatory power of the spoken word (Krienke, 2015). In the current political climate of many countries, where the populist right is growing in power, we would do well to remember the poetic justice of many historical revolutions. Literature functions as a mirror that reflects greater overarching discourses. Aside from its entertainment value, great literature holds the power to explain, question, and critique social phenomena.

Noted linguist Li Wei outlined his groundbreaking concept of translanguaging and discussed his current research. According to Wei, language systems are not individual facets of the human experience. Rather, each linguistic resource and repertoire constitutes a person as a holistic individual (Wei, 2011). This concept is especially relevant in a post-mobilities turn era in which "superdiverse" contexts (i.e. major metropolitan areas characterized by people of more diverse origins than ever before) are becoming more and more common (Vertovec, 2007). Given the globalization of information in current time of big data, this insight into language-based sense-making revolutionizes our approach to multilingualism and linguistic diversity. It shows us how and to what extent language as a means of communication is embedded in a fluid system of diverse subjectivities.

The concept of translanguaging underpinned many of the thematic foci. Language came to the fore as presenters discussed the relationship between lin- guistics, identity and migration. In contexts as diverse as Canada, the Netherlands, the Pacific Islands, Iran, and many others, the presentations demonstrated that language shapes and informs identity and is in turn shaped by it. Migration is a framework in which this mutually constitutive process takes place. The language we speak changes as it is shaped by specific cultural, social, economic, and political contexts. Many presentations discussed the concept of the introduction of new or different speakers of a similar language, and how this has an impact on how that language is spoken. One presentation on Mennonite Plautdietsch showed that the various language communities in North America to which it belongs disagree on pronunciation, use of neologisms and other aspects of this variation of Low German (Burns, 2016). Similarly, Francoprovencal, a language spoken in and near regions of Western Switzerland, is experiencing a revival as more non-native speakers are deciding to learn it for various reasons (Kasstan, 2017). In both cases, mobility (whether geographic or social) plays a huge role in the contact between the existing language group and other groups. These in-depth accounts highlighted how specific language groups negotiate change and evolution. They reinforce the consideration of global movement and the resulting contact between diverse groups as an inevitable and fascinating dynamic.

Ben Rogaly, a professor of Human Geography at the University of Sussex, supplemented the discussion of language use in mobility processes with his account of racism in the process of migration. Using data collected in the food sector, the research that he presented both illuminated and challenged conceptualizations of migration. The narratives which formed the body of his study provided examples of solidarities between workers of various nationalities, at all levels within the food industry (Regally \& Qureshi, 2017). Integrating theory within political research, the project called into question "common-sense" understandings of migration and exposed the ways in which discourses on migration perpetuate inequality in ac- 
cess to livelihood. It further explicated the phenomenon of contact due to migration, demonstrating the implications of interactions between groups classified as "new" or "migrant" and those classified as "local." Within his presentation, Professor Rogaly discussed the ways in which political solidarity can manifest in marginalized spaces between and amongst groups of differing national and ethnic origins. It also provided added insight into applications of linguistic research on migration, namely that academic engagement can have a political and emancipatory dimension.

Additionally, there was a strong focus on the main thematic element of identity based on migration history. Identity plays an integral part in the way that humans interact at both individual and societal levels. While much scholarship exists on the topic of identity, it remains a contested issue. Noted cultural studies scholar Stuart Hall views identity as a heuristic with which to engage broader questions. He notes that "identities are never unified and, in late modern times, increasingly fragmented and fractured; never singular but multiple constructed across different, often intersecting and antagonistic, discourses, practices and positions" (1996). Contemporary scholars note that identity can be deployed in the form of capital; identity is a concept to be negotiated, garnered and mobilized in various cultural contexts (Ho \& Bauder, 2012; Nowicka, 2013). The conference underscored this concept by presenting a broad array of understandings of the relationship between language, migration and identity, with many presentations noting the formative influence migration and language have upon identity. For example, a central point in many of the discussions after each presentation, particularly on the final day, was identity development after moving to a new context.

In what could be considered a response to previous discussion points, Ofelia Garcia discussed her pedagogical work in inner city New York primary and secondary schools (Garcia \& Lin, 2017). She complemented the concepts outlined earlier by saying that these schools are full of children with rich linguistic backgrounds, which could potentially be viewed as a resource. This position aligns with the aforementioned concept of "translanguaging." In the current paradigm, Garcia's research positions itself in contrast to a body of literature that outlines linguistic differences as an issue to be resolved. Her work with predominantly Spanish-speaking youth in lower-income neighborhoods in New York illuminates the challenges and rewards of conceptualizing language teaching as an opportunity, both for students and teachers. Many bodies of academic work and practitioner frameworks might benefit from this way of thinking. Such an approach improves upon an assimilationist view that suggests that newcomers must learn and speak only the prevalent national language. The narratives presented in Garcia's research offer us a poetic insight into the lives of migrants to the United States, showing the specific challenges they might find themselves facing. These challenges and subsequent successes have the potential for illuminating similar plights of migration and identity development across the world.

With migration and identity becoming increasingly important in the public sphere, insights based on critical analysis of intercultural, inter-linguistic, and various diverse forms of interaction become crucial for Switzerland and internationally. While the purpose of this report is to give an account of this conference on migration, language and identity, it would be incomplete without discussion of the critical impact that the flow of knowledge at such events represents.

The coming together of minds in this interdisciplinary way illustrates global flows of information. More broadly, the lines along which migration flows are heavily characterized by identities related to demographic characteristics like language, ethnicity, culture, etc. Boundaries that guide and separate are an integral part of the evolving processes of language evolution and identity construction. As both of these processes are deeply entrenched in the migration process, fully understanding their mutually constitutive relationship is crucial to a nuanced under- 
standing of how both physical and discursive boundaries are crossed. As a presentation on the discursive construction of borders in media texts demonstrated, borders are not only defined in terms of territory but also enacted through processes of differentiation. This discursive struggle over meaning takes place between social categories as well as physical locations. The either/or dynamic is an integral part of how individuals define themselves in relation to one other.

Not only do language and identity play a role in the understanding of larger contexts, they also play a role in shaping how those contexts are created. National identity, communicated through language, is an intrinsic aspect of the construction of the nation. Each populace is responsible for creating an imagined community that constitutes the nation. At the national level, this has very material repercussions for those deemed to be included and excluded within this community. Just as some people are "imagined into" the community, there are those who are "imagined out," often on the basis of identity and language. In times where migrant populations are taking up more and more space within the global imaginary, conferences like the Approaches to Migration, Language and Identity, are imperative in shaping global academic and non-academic discourses that frame how migrant populations are addressed, both symbolically and materially.

As noted migration scholar Janine Dahinden notes, contemporary scholars must move away from problematizing the migrant population by de facto asserting it as the unit of analysis (2016). One of the ways in which this change can be institutionally effected is by hosting interdisciplinary conferences in which the position of the migrant "Other" illuminates how dominant discourses contribute to the exclusion of marginalized communities at various levels. This conference provided those who attended with a forum for the generation and discussion of research ideas on how to address this phenomenon. The opportunity to speak to and learn from world-renowned scholars was invaluable for all involved, and provided enrichment to various perspectives on migration, language, and identity.

\section{References}

Burns, R. C. (2016). New world mennonite low German: An investigation of changes in progress. University of California, Berkeley.

Dahinden, J. (2016). A plea for the "de-migranticization" of research on migration and integration. Ethnic and Racial Studies, 39(13), 2207-2225.

Fairclough, N. (1995). Media discourse.

García, O., \& Lin, A. M. (2017). Extending understandings of bilingual and multilingual education. Bilingual and Multilingual Education, 1-20.

Hall, S., \& Du Gay, P. (Eds.). (1996). Questions of cultural identity: SAGE Publications. Sage.

Ho, M., \& Bauder, H. (2012). "We are chameleons": Identity capital in a multicultural workplace. Social Identities, 18(3), 281-297.

Kasstan, J. (2017). New speakers: Challenges and opportunities for variationist sociolinguistics. Language and Linguistics Compass, 11(8).

Krienke, Kai. (2015). The sun under the weapons, correspondence \& notes from Algeria. Center for the Humanities, the Graduate Center, The City University of New York.

Nowicka, M. (2013). Positioning strategies of Polish entrepreneurs in Germany: Transnationalizing Bourdieu's notion of capital. International Sociology, 28(1), 29-47.

Rogaly, B., \& Qureshi, K. (2017). “That's where my perception of it all was shattered": Oral histories and moral geographies of food sector workers in an English city region. Geoforum, 78, 189-198.

Tadmor, N. (2017). The settlement of the poor and the rise of the form in England, c. 1662-1780. Past and Present, 236(1), 43-97.

Vertovec, S. (2007). Super-diversity and its implications. Ethnic and racial studies, 30(6), 1024-1054.

Wei, L. (2011). Moment analysis and translanguaging space: Discursive construction of identities by multilingual Chinese youth in Britain. Journal of Pragmatics, 43(5), 1222-1235. 
Wessendorf, S. (2008). Culturalist discourses on inclusion and exclusion: the Swiss citizenship debate. Social Anthropology, 16(2), 187-202. 